\title{
A physics laboratory course designed using problem-based learning for prospective physics teachers
}

\author{
Cezmi Ünal ${ }^{*}$ and Ömer Faruk Özdemir² \\ 'Department of Education, Gaziosmanpaşa University, Tokat, Turkey \\ ${ }^{2}$ Department of Education, Middle East Technical University, Ankara, Turkey \\ For correspondence: cezmi@metu.edu.tr
}

\begin{abstract}
In general, laboratories are exercises with a primary focus on the verification of established laws and principles, or on the discovery of objectively knowable facts. In laboratories, students gather data without comprehending the meaning of their actions. The cognitive demand of laboratory tasks is reduced to a minimal level. To prevent these deficiencies, activities in a physics laboratory course were redesigned using problem-based learning. Problem-based learning is an inquiry based instructional design in which experiential learning organized around the investigation, explanation, and resolution of meaningful problems. In activities, instructional strategy is studentcentered and learning has to occur in small student groups under the guidance of a tutor. Authentic real world problems are primarily encountered in the learning sequence. To solve the problems, students propose hypothesis, and test their hypothesis with suitable experiment designs. Laboratory design and instruction strategies are very suitable for performing science process skills.
\end{abstract}

\section{Introduction}

Science educators increasingly perceive the school science laboratory as a unique learning environment in which students can work cooperatively in small groups to investigate scientific phenomena and relationships. Hofstein and Lunetta (1982) suggested that laboratory activities have the potential to enable collaborative social relationships as well as positive attitudes toward science and cognitive growth. The social environment in a school laboratory is usually less formal than in a conventional classroom. Thus, the laboratory offers opportunities for productive, cooperative interactions among students and with the teacher that have the potential to promote positive learning environment. The laboratory offers unique opportunities for students and their teacher to engage in collaborative inquiry and to function as a classroom community of scientists (Gunstone \& Champagne, 1990). Such experiences offer students opportunities to consider how to solve problems and develop their understanding. Better understanding of students' science process skills is important since all activities in the laboratory directly related to these skills.

Scholarly efforts have identified serious inconsistencies between goals for science education and learning outcomes visible in school laboratories. "Several researchers have reported that students regularly performed school science experiments with very different purposes in mind than those perceived by their teachers" (Lunetta, 2003). Students tended to perceive either following the instructions or getting the right answer as the principal purpose for a school science task. In the laboratory, students can perceive that manipulating equipment and measuring are goals but they can fail to perceive conceptual or even procedural goals. Students often fail to understand the relationship between the purpose of the investigation and the design of the experiment which they had conducted, they do not connect the experiment with what they have done earlier, and they seldom note the discrepancies between their own concepts, and the concepts of their peers. A laboratory means manipulating equipment but not manipulating ideas for many students (Eylon \& Linn, 1988). 


\section{Literature Review}

In recent years more importance has been placed on the learner's experience. The constructivist perspective of learning science emphasizes the importance of individual interpretation in the process of the construction of knowledge. "Constructivism implies that students require opportunities to experience what they are to learn in a direct way and time to think and make sense of what they are learning" (Tobin, 1990, p. 405). Students need to be able to arrive at an understanding of why they do, what they do, and to construct feasible explanations for their experiences, instead of completing a set of prescribed steps presented by another individual.

Inquiry can be a valuable pathway for the realization of constructivist perspective. In the United States National Science Education Standards (2000), inquiry is defined as the methods that "scientists study the natural world and propose explanations based on the evidence derived from their work. Inquiry also refers to the activities of students in which they develop knowledge and understanding of scientific ideas as well as an understanding of how scientists study the natural world" (p. 23). Inquiry/science process skills stem from how scientists' work and help students understand how scientists think, work and investigate their own questions. Martin (2000) classified the processes of scientific inquiry into "basic" and "integrated" process skills. Basic inquiry/process skills include observing, classifying, communicating, measuring, predicting, and inferring. On the other hand, integrated inquiry process skills include identifying and controlling variables, formulating and testing hypotheses, interpreting data, defining operationally, experimenting, and constructing models. Basic inquiry process skills are usually the main focus of inquiry-based classrooms. However, National Research Council (2000) recommended advancing aimed inquiry/ process skills one step forward and using integrated inquiry/ process skills such as "asking questions, planning and conducting investigations, using appropriate tools and techniques to gather data, thinking critically and logically about relationships between evidence and explanations, constructing and analyzing alternative explanations, and communicating scientific arguments" (p.105).

Laboratory activities have long had a distinctive and central role in the science education for promoting science process skills. Science educators have suggested that many benefits can be attained from engaging students in science laboratory activities (Lazarowitz \& Tamir, 1994). Lunetta (2003) defines laboratory activities as "experiences in school settings in which students interact with materials to observe and understand the natural world. Laboratory classes have ranged from activities in which data are gathered to verify a stated principle or relationship to inductive activities, in which students seek to identify patterns or relationships in data which they gather" (p. 249).

Teacher guidance and instruction have ranged from highly structured to open inquiry in laboratory activities. Laboratory classes have been conducted to engage students individually in small groups and in large-group demonstration settings. Sometimes laboratory activities have incorporated a high level of instrumentation and at other times the use of any instrumentation has been purposefully avoided (Gunstone \& Champagne, 1990). Laboratory activities can offer important experiences in the learning of science. Laboratory experiences have been supposed to promote central science education goals including: understanding of scientific concepts, the development of scientific practical skills and problem-solving abilities, and interest and motivation (Roth, 1994).

Among the problems cited as responsible for the deficiencies of laboratory experiences, two of them are very important (Tobin, 1990). First, current science teaching is embedded on an inappropriate epistemology. Laboratories are exercises with a primary focus on the verification of established laws and principles, or on the discovery of objectively knowable facts. In laboratories, students gathered data without comprehending the meaning of their actions. The cognitive demand of laboratory tasks was reduced to a minimal level. Second, collaborative methods are not used properly in science laboratories. Students work on their assignments in a leisurely atmosphere and spent much of their time off-task, socializing with their peers.

From a constructivist perspective, the collaboration among students has great potential since group interactions provide an opportunity for the negotiation of meaning and arriving at consensus, important mechanisms in the equilibration of discrepancy and disagreement (Wheatley, 1991). The 
nature of the interactions among students and research teams in the school laboratory can enhance science concept construction and related learning outcomes. When teachers utilize cooperative learning strategies, researchers have reported better integration between classroom and laboratory activity and enhanced achievement (Johnson et al., 1985). Collaborative planning and discussions of findings provide a forum in which implicit ideas can be made explicit. Communication and reflection are encouraged through the preparation and discussion of laboratory reports. Preparing a report should provide opportunities for individual students to reflect upon and clarify their own observations, hypotheses, conceptions and theories. Dialogue also provides opportunities for individuals to build on the ideas of others to reach understanding and solutions (Lazarowitz \& Tamir, 1994).

Collaborative methods provide situations where participants must offer explanations, interpretations, and resolutions to problems (Brown \& Palincsar, 1989). Several studies conducted in science courses reported positive effects of cooperative learning methods (Okebukola, 1985; Johnson et al., 1985). Although some studies have lighted on science learning in groups, the literature available remains limited. Additionally, most of these research agendas were conducted in the process-product paradigm and usually had not described what are the learning processes in detail (Eylon \& Linn, 1988).

Problem-based learning is an inquiry based instructional design in which experiential learning organized around the investigation, explanation, and resolution of meaningful problems (Borrows, 2000). In spite of the many variations of problem-based learning that have evolved, six core characteristics of problem-based learning are distinguished in the core model described by Barrows (1996). The first characteristic is that learning needs to be student-centered. Second, learning has to occur in small student groups under the guidance of a tutor. The third characteristic refers to the tutor as a facilitator or guide. Fourth, authentic problems are primarily encountered in the learning sequence, before any preparation or study has occurred. Fifth, the problems encountered are used as a tool to achieve the required knowledge and the problem-solving skills necessary to eventually solve the problem. Finally, new information needs to be acquired through self-directed learning.

\section{Laboratory worksheets}

Six laboratory worksheets were prepared in line with characteristics of problem-based learning. Two research assistants checked the cases and the parts of laboratory worksheets.

All laboratory worksheets consist of 9 parts. At the first part there is a problematic real life context which can be encountered during the daily life of people. Participants read this situation and think about it. They should understand the context and problem, and propose some solutions to the problem. The cases were developed with the following consideration.

- Situations can be encountered in real life

- More than two variables in the problems

- The availability of lab equipments for possible experiments

- Problems from different topics

IN the first question, students need to identify physics concepts that can be related to situation. Second question wants participants write the problem of the case by using these physics concepts. First and second questions provide analysis of the real life situation from a physicist's perspective. Moreover, answers to these questions will show that in what degree students understand the situation and problem. Students write a hypothesis to solve the problem in the fourth part. At the fifth part, they design an experiment to test their hypothesis. They should explain their experiment, draw a scheme of their experiment and write numerical values of their controlled variables. In the sixth part participants write their variables. Variables are divided into subgroups as manipulated, responding, controlled, and uncontrolled variables. At the seventh part, they write their experiment results with tables and graphs. Eight part of the worksheet consist of their interpretation of the experiment and results. Participants should write limitation of their experiment and in what degree they believe their results. At the last part, they should write a recommendation as a solution to the problem. 


\section{Implementation of the Method}

The study began at the fall semester of 2008-2009. There were 18 participants in the study. Because of the laboratory conditions they divided into two groups. Participants worked with pairs according to who they wanted to work with. At the first week laboratory work sheets were introduced to participants. What they are going to do in the laboratory and how they should fill the laboratory worksheets were shortly described. The study spanned to six weeks period of three hours per week. At the first five weeks laboratory worksheets were given to the participants. For the last week, participants prepared their laboratory worksheets similar to their previous worksheets. Alternative laboratory worksheet for sixth week was also prepared by the researcher in case participants would have not prepared it. Every week at the end of the lessons, there was a discussion part in which every group presents their hypothesis, experiment design, results, and their recommendation.

There were two laboratory assistants during the study, one of them researcher.

The other laboratory assistant was informed about laboratory worksheets, situations, and possible experiments. Laboratory assistants did not provide any guidance to the participants without participants asked for help.

\section{Conclusion}

In general, laboratory activities were implemented for six weeks successfully. Students worked with given laboratory worksheets for five weeks. At the last week, all groups prepared their own worksheets and worked on their topics. Laboratory worksheets and observations of these laboratory sessions indicated the participants' competency of science process skills. During the activities students encountered with many difficulties. However, these difficulties were decreased throughout laboratory sessions. For example, students could not identify the possible variables for the cases in the early weeks. They only paid attention on manipulated and responding variables. As a result of this, they did not try to keep constant some important variables that could affect their design. On the other hand, they began to identify more variables and consider these variables in the later laboratory sessions. These also showed that participants need to conduct more problem-based laboratory activities for improving their competency on science process skills.

\section{References}

Barrows, H. S. (2000). Problem-based learning applied to medical education. Southern Illinois University Press, Springerfield.

Barrows, H. S. (1996). Problem-based learning in medicine and beyond. In L. Wilkerson \& W. H. Gijselaers (Eds.), New directions for teaching and learning: Vol. 68. Bringing problem-based learning to higher education: Theory and practice (pp. 3-13). San Francisco: Jossey-Bass.

Brown, A. L. \& Palincsar, A. S. (1989). Guided cooperative learning and individual knowledge

acquisition. In L. B. Resnick (ed.), Knowing, Learning, and Instruction (pp. 393-451). Hillsdale: Erlbaum.

Eylon, B., \& Linn, M. C. (1988). Learning and instruction: An examination of four research perspectives in science education. Review of Educational Research, 58(3), 251-301.

Gunstone, R. F., \& Champagne, A. B. (1990). Promoting conceptual change in the laboratory. In E. Hegarty-Hazel (Ed.), The student laboratory and the science curriculum (pp. 159-182). London: Routledge.

Hofstein, A., \& Lunetta, V. N. (1982). The role of the laboratory in science teaching: Neglected aspects of research. Review of Educational Research, 52(2), 201-217.

Johnson, R. T., Johnson, D. W., Scott, L. E. and Ramolae, B. A. (1985). Effects of single-sex and mixed-sex cooperative interaction on science achievement and attitudes and cross-handicap and cross-sex relationships. Journal of Research in Science Teaching, 22 (3), 207-220.

Lazarowitz, R., \& Tamir, P. (1994). Research on using laboratory instruction in science, In D. L. Gabel (Ed.), Handbook of research on science teaching and learning (pp. 94-130). New York: Macmillan.

Lunetta, V. N. (2003). The school science laboratory: Historical perspectives and contexts for contemporary teaching. In B.J. Fraser \& K.G. Tobin (Eds.), Handbook of Science Education (pp. 249-262). Great Britain: Kluwer Academics Publishers.

Martin, D. J. (2000). Elementary science methods: A constructivist approach. Belmont, CA: Wadsworth.

National Research Council. (2000). Inquiry and the national science education standards: A guide for teaching and learning. Washington DC: National Academy Press.

Okebukola, P. A. (1985). The relative effectiveness of cooperative and competitive interaction techniques in strengthening students' performance in science classes. Science Education, 69(4), 501-509.

Roth, W. M. (1994). Experimenting in a constructivist high school physics laboratory. Journal of Research in Science Teaching, 31, 197-223.

Tobin, K. G. (1990). Research on science laboratory activities: in pursuit of better questions and answers to improve learning. School Science and Mathematics, 90(5), 403-418. 
Wheatley, G. H. (1991). Constructivist perspectives on science and mathematics learning. Science Education, 75 (1), 9-21.

\section{Appendix}

Sample Laboratory Worksheet

\section{THE JUNKYARD}

In a junkyard, Mr. Üstün, the owner of the junkyard, uses big electromagnet cranes to move old cars. The electromagnet crane he uses is able to lift standard-sized cars easily. However, Mr. Üstün has realized that it is not appropriate for holding bigger cars, such as SUVs, which are two times heavier than usual cars. Because Mr. Üstün cannot afford to buy a new electromagnet crane, he tries to make a more powerful electromagnet crane by doing some changes using the materials that are available in his junkyard. Can you give some advice to Mr. Üstün on this issue as a physicist?

What can be the physics concepts related to this situation?

What is the main problem of Mr. Üstün when you look at from a physicist's perspective?

Write a hypothesis that may provide a solution to the problem:

Design an experiment to test your hypothesis in the laboratory:

What are the variables that can affect your experiment?

Manipulated:

Responding:

Controlled:

Uncontrolled:

Your results and observations:

Interpretation of your results and observations:

What is your recommendation to Mr. Üstün? 